\title{
O JORNAL "A FÍSICA ONTEM E HOJE" COMO INSTRUMENTO DE DIVULGAÇÃO E DISCUSSÃO CIENTÍFICA DENTRO E FORA DO AMBIENTE ESCOLAR
}

\section{THE NEWSPAPER "THE PHYSICS YESTERDAY AND TODAY” AS A INSTRUMENT TO DISCUSSIONS AND DIVULGATION OF SCIENCE INSIDE AND OUTSIDE THE SCHOOL}

\author{
João Paulo Casaro Erthal \\ Universidade Federal do Espírito Santo / Departamento de Química e Física, jperthal@gmail.com
}

\section{Resumo}

Neste trabalho é apresentado um relato de produção e de utilização de um jornal sobre ciências que objetiva despertar o interesse dos estudantes do ensino médio sobre temas científicos, promover discussões sobre ciência no ambiente escolar, desenvolver competências específicas nesses estudantes e divulgar ciências para a população local. O jornal intitulado "A Física Ontem e Hoje" possui uma versão impressa, com tiragem média de duzentos e cinquenta exemplares por edição, a qual é disponibilizada em diferentes contextos; e uma versão exclusivamente online, geralmente com informações extras, de acesso livre. A utilização dos jornais em sala de aula tem auxiliado no desenvolvimento de habilidades de leitura e interpretação de textos por parte dos estudantes e despertado a curiosidade desses por temas específicos. A sociedade civil e acadêmica que tem tido acesso ao jornal recebeu de forma positiva o material e teceu comentários favoráveis à proposta e às temáticas abordadas.

Palavras-chave: Divulgação Científica, Ensino de Física.

\section{Abstract}

In this work is presented a report of production and use of a newspaper about science that aims to awaken the interest of students about scientific topics, promote science discussions at school, develop specific skills in this students and disseminate science to the local population. The newspaper entitled "The Physical Yesterday and Today" has a printed version, with average circulation of two hundred and fifty copies per edition, which is available in different contexts, and an exclusive online version, usually with extra information, and free access. The use of newspapers in the classroom has helped in the development of reading skills and interpretation of texts by students and aroused the curiosity of those for specific topics. Civil society and academic who has been had access to the newspaper received a positive material and weaved favorable comments about the themes addressed.

Keywords: Scientific Divulgation, Physics Teaching. 


\section{Introdução}

Muitas são as críticas feitas ao ensino de Física no ensino médio. Talvez uma das mais contundentes seja a desvinculação entre os conteúdos contidos no livro texto e a realidade vivenciada pelos alunos, a qual tem levado professores e estudantes de Física a certas frustrações e situações, um tanto quanto, desanimadoras. Atrelado a isso, a precariedade da infraestrutura das escolas, principalmente públicas, e a reduzida carga horária atribuída à disciplina, tornam extremamente difícil construir uma rotina em que a relação professor-aluno traga a tona apropriações para uma visão crítica, realista e aplicada da Física.

Porém, os problemas enfrentados não se resumem aos que foram citados e relacionam-se também a um legado trazido do ensino fundamental no que tange à falta de aquisição de habilidades básicas pelos estudantes, que, em muitos casos, chegam ao ensino médio sem condições de acompanhar o andamento da disciplina devido à falta de habilidades específicas. No trabalho de Erthal (2011) foi realizada uma pesquisa com dezesseis professores de Física do ensino médio, na modalidade de Educação para Jovens e Adultos, buscando-se identificar quais fatores tais professores consideravam ser os impasses no processo de ensino e aprendizagem de Física com suas turmas. Os resultados mostraram que a falta de conhecimentos matemáticos e a falta de habilidades de leitura são os fatores que mais dificultam o trabalho dos professores com suas turmas.

De acordo com o trabalho de Ricardo e Freire (2007) existe uma percepção negativa dos estudantes do ensino médio quanto à disciplina de Física, principalmente em relação à sua utilidade prática. Em muitos casos, isso ocorre mesmo antes do estudante ter conhecimento sobre os ramos de estudo dessa ciência. Corroborando com essa ideia, D'Agostin e colaboradores (2006) concluíram que a aversão dos estudantes do ensino médio em relação à disciplina de Física aumenta com o passar dos anos, sendo maior entre estudantes do terceiro ano e menor entre estudantes do primeiro ano. Esse resultado é preocupante, uma vez que os estudantes têm se distanciado de conhecimentos físicos ao invés de se apropriarem deles de modo a empregá-los em seu cotidiano.

Cabe salientar que o currículo do ensino médio para o conteúdo de Física é muito extenso e que o professor tem uma carga horária pequena para conseguir discutir de maneira minimamente suficiente todo o objetivo previsto. Atrelado a isso, existe uma preocupação com foco na futura aprovação dos estudantes em exames e poucas são as iniciativas que realmente trabalham buscando a formação de cidadãos com um olhar crítico e reflexivo a respeito do mundo, dos acontecimentos e das tecnologias atuais.

É indispensável na formação dos estudantes do ensino médio o desenvolvimento de habilidades e competências que os permitam desvendar, investigar, compreender e se posicionar perante diferentes situações. Destacam-se algumas competências básicas para tal, as quais estão presentes nas orientações educacionais complementares aos Parâmetros Curriculares Nacionais para a área de Física:

Ler e interpretar informações apresentadas em diferentes linguagens e representações (técnicas) como, por exemplo, um manual de instalação de 
equipamento, características de aparelhos eletrodomésticos, ou esquemas de montagem de móveis. (BRASIL, 2002, p. 8)

Compreender e emitir juízos próprios sobre notícias com temas relativos à ciência e tecnologia, veiculadas pelas diferentes mídias, de forma analítica e crítica, posicionando-se com argumentação clara. Por exemplo, enviar um e-mail contra argumentando uma notícia sobre as vantagens da expansão da geração termoelétrica brasileira. (BRASIL, 2002, p. 9)

Compreender o desenvolvimento histórico da tecnologia, nos mais diversos campos, e suas consequências para o cotidiano e as relações sociais de cada época, identificando como seus avanços foram modificando as condições de vida e criando novas necessidades. Esses conhecimentos são essenciais para dimensionar corretamente o desenvolvimento tecnológico atual, através tanto de suas vantagens como de seus condicionantes. Reconhecer, por exemplo, o desenvolvimento de formas de transporte, a partir da descoberta da roda e da tração animal, ao desenvolvimento de motores, ao domínio da aerodinâmica e à conquista do espaço, identificando a evolução que vem permitindo ao ser humano deslocar-se de um ponto ao outro do globo terrestre em intervalos de tempo cada vez mais curtos e identificando também os problemas decorrentes dessa evolução. Compreender o desenvolvimento histórico dos modelos físicos para dimensionar corretamente os modelos atuais, sem dogmatismo ou certezas definitivas. (BRASIL, 2002, p. 14)

Acompanhar o noticiário relativo à ciência em jornais, revistas e notícias veiculadas pela mídia, identificando a questão em discussão e interpretando, com objetividade, seus significados e implicações para participar do que se passa à sua volta. Por exemplo, no noticiário sobre telefonia celular, identificar que essa questão envolve conhecimentos sobre radiações, suas faixas de frequência, processos de transmissão, além de incertezas quanto a seus possíveis efeitos sobre o ambiente e a saúde. (BRASIL, 2002, p. 8)

Apesar dessas orientações, o ensino de Física, na forma como vem sendo feito no ensino médio, geralmente não favorece o desenvolvimento de tais competências e se restringe ao uso da linguagem matemática atrelada às substituições em formalismos marcadas pela falta de reflexões teóricas.

Entretanto, é fundamental que o ensino de Física possa contribuir para o desenvolvimento de tais competências. Para alcançar este objetivo, é essencial a utilização de uma linguagem cientificamente adequada e de fácil compreensão, em situações contextualizadas que despertem o interesse dos estudantes e que os entusiasmem na busca por novas informações. Em vista disso, este trabalho apresenta um material com essas características, nos moldes de um jornal, chamado "A Física Ontem e Hoje", assim como as atividades realizadas com ele e sua contribuição na divulgação científica dentro e fora do ambiente escolar no município de Alegre, Estado do Espírito Santo.

\section{O Jornal "A Física Ontem e Hoje"}

O jornal "A Física Ontem e Hoje", foi criado em 2013 com o intuito de tentar difundir ciência com mais facilidade e eficiência, além de levar aos estudantes conhecimentos 
teóricos e práticos relacionados à Física, de maneira contextualizada e com uma linguagem científica reelaborada, de forma que seja acessível ao público em geral, sobre temas interessantes e relacionados às tecnologias e aos acontecimentos cotidianos e históricos.

A ideia inicial de confecção do material ocorreu após a identificação do desinteresse de estudantes de duas escolas estaduais no município de Alegre em relação à leitura de textos relacionados à ciência e do descaso de muitos deles em relação ao estudo de conceitos físicos.

Até junho de 2016 foram confeccionadas 17 edições do jornal, com uma tiragem média de 250 exemplares impressos por edição. Também são produzidas versões exclusivamente online do jornal, as quais geralmente são mais robustas e possuem textos mais extensos e detalhados quando comparados aos do jornal impresso.

A versão exclusivamente online permite que os leitores da versão impressa corrijam atividades ou busquem novas informações. Ambas as versões, impressa e online, ficam disponibilizadas no site: http://www.fisica.alegre.ufes.br/jornal-do-pibid, de modo que qualquer interessado possa ter acesso às versões do jornal, contribuindo para alargar as possibilidades de divulgação científica desse material, sendo esse um dos objetivos desta proposta. A divulgação científica no ensino de ciências tem gerado diversos trabalhos acadêmicos e, sem dúvida, é uma excelente estratégia para a redução do analfabetismo científico. De acordo com Ribeiro e Kawamura (2006) a divulgação científica é um processo que veicula informações sobre ciência e tecnologia por meio de recursos e técnicas diversificadas para o público em geral.

De forma ilustrativa, apresenta-se a figura 1 com a capa de alguns dos jornais produzidos.

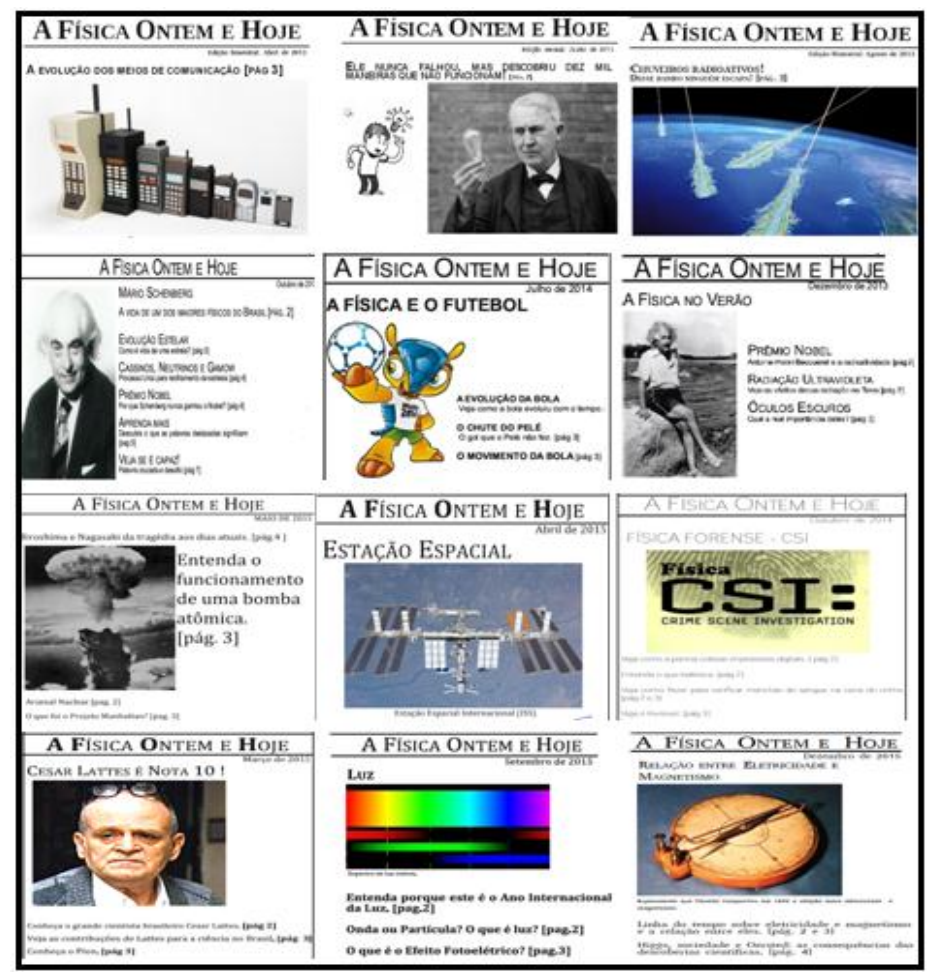

Figura 1: Capas de algumas edições do jornal "A Física Ontem e Hoje". 
Cada edição do jornal possui um tema central e todos os jornais têm em média quatro pequenos textos que tratam de assuntos relacionados ao referido tema. Nesses textos, os conceitos físicos são abordados de maneira clara e de fácil compreensão, com exemplos práticos e curiosidades. As versões impressas contam com atividades relacionadas aos textos do jornal, tais como: caça palavras, questões desafio e palavras cruzadas. As respostas dessas atividades são sempre apresentadas na versão exclusivamente online. Além disso, nas versões impressas existem palavras em negrito, as quais possuem seu significado transcrito em um glossário na versão exclusivamente online, de modo a instigar os estudantes a acessarem ambas as versões. Os jornais são repletos de signos linguísticos, matemáticos e científicos.

A escolha do tema do jornal geralmente se dá pela pesquisa de temas atuais e que tenham potencial em despertar o interesse do leitor, ou é fruto de um planejamento em relação a temas que o professor virá a lecionar em sala de aula, de modo que esse possa ser um material auxiliar durante a explanação do conteúdo. Os jornais buscam sempre contemplar elementos presentes nos temas estruturadores existentes nos Parâmetros Curriculares Nacionais (BRASIL, 2002).

São destacados cientistas e personalidades importantes para os avanços científicos e tecnológicos que se relacionam aos temas, trazendo ao leitor informações sobre a construção que é realizada constantemente na ciência. Em determinadas edições são trazidas informações sobre cientistas laureados com o prêmio Nobel de Física, com intuito de despertar o interesse do leitor pelo assunto, de fomentar discussões em sala de aula, e de possibilitar a relação dos tópicos que estão sendo explanados em sala de aula aos grandes cientistas que auxiliaram no desenvolvimento desse conhecimento. Existem edições do jornal que tratam exclusivamente de importantes cientistas brasileiros de modo que se tenha uma maior valorização desses cientistas perante a sociedade.

Algumas edições trazem informações sobre as Olimpíadas Brasileiras de Física, as Olimpíadas Brasileiras de Física para a Escola Pública e as Olimpíadas Brasileiras de Astronomia, em caráter informativo para os estudantes do ensino médio.

A tabela 1 traz os temas das edições do jornal confeccionadas e disponibilizadas.

Tabela 1: Edições do jornal "A Física Ontem e Hoje".

\begin{tabular}{|l|l|}
\hline Edições & Tema \\
\hline $1^{\underline{a}}$ & A Evolução da Telefonia \\
\hline $2^{\underline{a}}$ & Eletricidade: uma ideia iluminada \\
\hline $3^{\underline{a}}$ & Raios Cósmicos \\
\hline $4^{\underline{a}}$ & Mário Schenberg \\
\hline $5^{\underline{a}}$ & A Física no Verão \\
\hline $6^{\underline{a}}$ & A Física da Chuva \\
\hline $7^{\underline{a}}$ & A Física e o Futebol \\
\hline
\end{tabular}




\begin{tabular}{|l|l|}
\hline $8^{\underline{a}}$ & Física Forense - CSI \\
\hline $9^{\underline{a}}$ & A Física e a Fórmula 1 \\
\hline $10^{\underline{a}}$ & César Lattes é nota 10 \\
\hline $11^{\underline{a}}$ & Estação Espacial \\
\hline $12^{\underline{a}}$ & Bomba Atômica \\
\hline $13^{\underline{a}}$ & Especial de Esportes Olímpicos - Tiro com Arco \\
\hline $14^{\underline{a}}$ & Luz \\
\hline $15^{\underline{a}}$ & Especial de Esportes Olímpicos - Esportes Aquáticos \\
\hline $16^{\underline{a}}$ & Relação entre Eletricidade e Magnetismo \\
\hline $17^{\underline{a}}$ & Queda dos Corpos \\
\hline
\end{tabular}

A primeira edição trata da evolução dos meios de comunicação com foco na telefonia, assunto que desperta 0 interesse dos estudantes pelo fato de telefones celulares serem utilizados massivamente pelos alunos nos dias atuais, seja para se comunicar, jogar, fotografar, ouvir música, ver vídeos, pesquisar ou como ferramenta de trabalho. Nessa edição há um pequeno texto falando sobre o prêmio Nobel de Física de 1909, cujo premiado foi Guglielmo Marconi, por suas contribuições para o desenvolvimento do telégrafo sem fio. Apenas a título de exemplo, essa edição relacionase aos temas estruturadores: Equipamentos Eletromagnéticos e Telecomunicações; e Som imagem e Informação.

A segunda edição fala de eletricidade e iluminação e traz um texto sobre Thomas Edson e algumas de suas grandes invenções, com foco na lâmpada incandescente que possibilitou maior eficácia na iluminação pública e domiciliar. Explana também sobre Nikola Tesla e seu ideal na busca por formas eficientes para se transmitir a energia elétrica. Eletricidade e sua utilização para iluminação é um tema com grande potencial para discussões e reflexões, uma vez que o mundo moderno, provavelmente, não seria 0 mesmo sem a existência de tal tecnologia.

A terceira edição traz a tona os raios cósmicos abordando a descoberta dessa radiação e falando sobre personagens importantes relacionados ao tema, como o cientista norte americano Carl David Anderson, laureado com prêmio Nobel de Física em 1936 pela descoberta do pósitron, e o cientista brasileiro César Lattes, que auxiliou na comprovação da existência da partícula méson pí. Esse jornal possibilita a discussão de assuntos relacionados à Física moderna em sala de aula, temática pouco presente no ensino médio.

A quarta edição homenageia um importante cientista brasileiro, Mario Schenberg, tratando resumidamente sobre a vida, obra e legado desse cientista, que trabalhou com diversos cientistas internacionais, sendo alguns deles laureados com o prêmio Nobel de Física, e que teve seu nome atrelado ao tempo de colapso gravitacional de uma estrela, 
chamado de limite de Schenberg-Chandrasekhar. Há ainda nessa edição textos sobre a evolução estelar além do glossário e de curiosidades sobre astrofísica.

A quinta edição, divulgada no início do mês de dezembro, fala sobre a Física no verão trazendo textos sobre radiação ultravioleta, conceitos relacionados à radioatividade e aborda o prêmio Nobel de 1903, dado a Henry Becquerel devido a seus estudos sobre radioatividade, assunto esse que apareceu bastante na mídia devido ao acidente na usina nuclear de Fukushima em 2013.

A sexta edição fala sobre a Física das chuvas, explicando fenômenos naturais como formação de nuvens, relâmpagos e trovões. Esse tema pode fomentar várias discussões no ambiente escolar, visto que o Brasil é o país que mais recebe descargas elétricas dessa natureza no mundo. Traz ainda um texto que aborda como são medidos os índices pluviométricos, explicando ao leitor como são calculadas e realizadas as previsões da quantidade de chuva para uma determinada região.

A sétima edição aborda o esporte mais popular no Brasil e sua relação com conceitos físicos. Essa edição foi lançada próxima ao acontecimento da Copa do Mundo de Futebol no Brasil, trazendo informações interessantes sobre a evolução das bolas de futebol, o efeito Magnus, e os conceitos físicos relacionados ao movimento de uma bola. A questão desafio dessa edição traz a tona o gol que Pelé não fez na Copa do Mundo de 1970, ao chutar uma bola do meio de campo em direção ao gol.

A oitava edição fala sobre o papel da Física nas investigações criminais, tema com grande potencial para despertar a curiosidade dos leitores, uma vez que o assunto tem aparecido em diversas séries televisivas e em filmes. São apresentados textos sobre balística, coleta de digitais e técnicas para enxergar objetos e marcas praticamente não visíveis a olho nu. Na versão exclusivamente online há um texto falando sobre o processo de funcionamento do etilômetro, conhecido popularmente como bafômetro. Os textos desse jornal permitem a discussão de tópicos diversos relacionados à ciência, desde lançamento de projéteis até as radiações presentes no espectro da luz visível e os processos de oxidação e redução de elementos químicos.

A nona edição aborda a Física da Fórmula 1, competição demasiadamente apreciada por muitos brasileiros. Os textos que compõem esse jornal contém informações sobre a propagação do som dos motores, a força de arrasto relacionada à estabilidade dos carros de competição, além de como as tecnologias da Fórmula 1 auxiliam no desenvolvimento de melhorias e benefícios para o setor automotivo.

A décima edição homenageia um dos mais importantes cientistas brasileiros, Cesar Lattes, trazendo a tona um pouco de sua vida e de suas principais contribuições para o desenvolvimento da ciência no Brasil. Além disso, há um texto que traz esclarecimento sobre partícula píon, descoberta em 1947 no Reino Unido com participação de César Lattes, Cecil Powel e Giuseppe Occhialini.

A décima primeira edição trata da Estação Espacial Internacional e traz explicações sobre o que é a estação, quais são os países que participam do projeto além de indicações para o leitor de um site disponibilizado pela Nasa e de um aplicativo que permitem a visualização do que está ocorrendo na estação espacial. 
A décima segunda edição trata da Bomba Atômica e traz a tona informações sobre o que foi o projeto Manhattan, sobre enriquecimento de urânio, sobre o funcionamento de uma bomba nuclear e sobre a tragédia de Hiroshima e Nagasaki. Traz ainda informações sobre os países que dominam tal tecnologia e fala sobre Julius Robert Oppenheimer, um dos pioneiros nos estudos sobre energia atômica.

A décima terceira edição tem o foco em esportes olímpicos, tendo em vista as Olimpíadas de $2016 \mathrm{com}$ sede no Brasil. O esporte escolhido foi tiro com arco e trouxe a tona textos sobre a história do arco e flecha, a Física do arco, e os tipos de arco existentes. A questão desafio dessa edição explora a energia potencial relacionada a um tiro com arco. Na versão exclusivamente online há um texto sobre a relação do índio e o arco e flecha e a participação do indígena brasileiro nos jogos olímpicos.

$\mathrm{Na}$ décima quarta edição o tema foi Luz, em homenagem ao ano de 2015, elencado pela Assembleia Geral das Nações Unidas como Ano Internacional da Luz. Vários eventos da área de Física e vários exames, por exemplo, as Olimpíadas Brasileiras de Física e o Simpósio Nacional de Ensino de Física, utilizaram o tema Luz nesse ano e, em vista disso, nada mais justo do que aproveitar que o tema estava em alta e fazer uma edição do jornal sobre o assunto. Nessa edição são apresentados textos falando sobre o ano internacional da luz, a dualidade onda-partícula e o efeito fotoelétrico. A versão exclusivamente online traz textos sobre espectroscopia e polarização da luz.

A décima quinta edição também tem o foco em esportes olímpicos, particularmente em alguns esportes aquáticos, falando sobre elementos da Física envolvidos na natação, no remo e em barcos a vela. Há um texto falando sobre empuxo e suas principais propriedades e nos outros textos são tratados tópicos como densidade, força de resistência hidrodinâmica e força de propulsão.

A décima sexta edição teve como tema a relação entre eletricidade e magnetismo, na qual é apresentada uma linha do tempo sobre os conceitos de eletricidade e magnetismo, além de um texto sobre o Bóson de Higgs e outro sobre auroras boreais. $\mathrm{Na}$ versão exclusivamente online, os textos são mais detalhados e é evidenciado o experimento de Oersted, que foi crucial para o estabelecimento de relações entre esses dois ramos da Física.

Por fim, na décima sétima edição foi abordada a queda livre dos corpos, com um breve histórico sobre as ideias divergentes de Aristóteles e Galileu sobre a queda dos corpos, um texto falando sobre o movimento de queda livre das torres gêmeas no atentado terrorista de 2001 nos EUA, e um texto explicando por que a lua não cai sobre a Terra. Na versão exclusivamente online há explanações sobre a queda livre de corpos na lua, sobre o experimento do plano inclinado de Galileu e sobre aplicações da queda livre no cotidiano.

\section{Utilização do Jornal no Ensino de Física}

Diversas são as maneiras como o jornal "A Física Ontem e Hoje" pode ser utilizado. Atualmente, o jornal é utilizado em três diferentes vertentes: 
A primeira delas é a utilização do jornal por professores do ensino médio e bolsistas de iniciação à docência, dentro do ambiente escolar, como ferramenta capaz de auxiliar na alfabetização científica e no desenvolvimento de habilidades de leitura, compreensão de textos e resolução de problemas. Os jornais são trabalhados nas diferentes séries do ensino médio, e a atividade pode ser iniciada com a leitura e interpretação dos textos por grupos de estudantes ou individualmente. $O$ professor pode optar por iniciar propondo desafios aos estudantes, de modo que resolvam questões desafio, palavras cruzadas ou caça palavras do jornal em questão. Podem ser sugeridas atividades extraclasse, com apoio das informações extras contidas nas versões exclusivamente online, além de poder-se utilizar os textos ou o tema do jornal como base para pesquisas escolares mais específicas e aprofundadas. Além disso, o jornal também vem sendo utilizado nos murais da escola, para que as informações contidas sejam acessíveis a todos os discentes. As décima sexta e décima sétima edições foram utilizadas de forma especial durante inserções realizadas pelos bolsistas de iniciação à docência em turmas específicas, nas quais o jornal foi um dos elementos utilizados para alavancar as discussões em sala de aula. A título de exemplo, o jornal sobre a queda dos corpos traz um texto com as ideias de Aristóteles e de Galileu sobre o assunto, e esse serviu de ancoradouro para um teatro realizado pelos bolsistas no qual caracterizaram tais personagens e defenderam as diferentes teorias sobre o assunto com argumentos e experimentos demonstrativos.

A segunda vertente de utilização do jornal é realizada com divulgação do jornal para a sociedade, de modo a despertar o interesse da população em geral por temas científicos. Uma tiragem de cinquenta jornais é disponibilizada em uma banca de jornal do município, e possui distribuição gratuita para os interessados. Relatos do jornaleiro apontam para uma boa aceitação da sociedade e que em menos de um dia os exemplares deixados na banca são retirados pelos interessados. Além disso, em eventos de divulgação científica da universidade, dentro do campus ou nas praças públicas do município, são distribuídas cópias de todas as edições existentes.

A terceira vertente acontece dentro do campus universitário, no qual cada nova edição do jornal fica disponibilizada no mural do curso de Licenciatura em Física, alguns exemplares são distribuídos pelos bolsistas de iniciação à docência na fila do restaurante universitário e outros são deixados no balcão da biblioteca. Estudantes de diferentes cursos de graduação teceram elogios aos temas apresentados e a abordagem dada pelo jornal.

\section{Considerações finais}

As atividades desenvolvidas com os jornais nas salas de aula do ensino médio têm propiciado uma aproximação entre o estudante e os temas científicos que, muitas vezes, não são abordados ou discutidos no ambiente escolar, ajudando a desenvolver uma maior consciência crítica e propiciando uma maior relação entre a sala de aula e os conhecimentos históricos ou as tecnologias atuais relacionados a temas diversos.

As diferentes atividades que podem ser realizadas com os jornais têm trazido excelentes resultados dentro de sala de aula. De acordo com o relato dos professores 
envolvidos, houve aumento no interesse dos estudantes em relação à leitura de assuntos científicos, melhora na qualidade da leitura de textos realizada por alguns desses estudantes e, consequente, melhora na escrita. Esses resultados estão de acordo com pesquisas que apontam para o desenvolvimento do hábito de leitura a partir da utilização de textos de divulgação científica (ANDRADE e MARTINS, 2004).

Além disso, o jornal traz conhecimentos cotidianos amplos e interdisciplinares, permitindo que os estudantes conheçam melhor a aplicação de conceitos de ciência e tecnologia em situações diárias. Esse contato com informações atualizadas sobre ciência e tecnologia possibilita a valorização dos conhecimentos obtidos em aula devido à conexão desses com o cotidiano dos estudantes, além de propiciar a articulação entre cultura científica e cultura escolar.

A incorporação dos jornais como recurso educacional auxiliar para turmas de ensino médio aponta na direção das novas tendências curriculares, assim como de novas concepções sobre a educação científica. A diversidade de abordagens presentes nas 17 edições permite que professores possam utilizar os jornais em atividades nos mais variados níveis de ensino.

Segundo Fontanella e Meglhioratti (2013), é necessário que os estudantes se aproximem do discurso científico veiculado nas mídias para uma melhor compreensão dos conteúdos curriculares e para o desenvolvimento da capacidade de argumentação em relação aos assuntos divulgados. O jornal "A Física Ontem e Hoje" tem propiciado, mesmo ainda em pequena escala, essa aproximação dos estudantes com o discurso científico.

O projeto do jornal continua ativo e novas edições estão sendo desenvolvidas. A próxima tem foco nos conceitos de hidrostática. Essa edição também será utilizada para uma inserção dos bolsistas de iniciação a docência em turmas específicas do ensino médio.

Como perspectivas futuras, pretende-se confeccionar alguns jornais especiais com foco em cientistas laureados com o prêmio Nobel de Física e desenvolver atividades nas quais os estudantes do ensino médio, que usufruem do jornal, possam produzir edições voltadas para estudantes do ensino fundamental, aumentado, assim, o quantitativo de habilidades desenvolvidas durante a formação desses estudantes.

A distribuição dos jornais dentro do campus universitário e sua exposição no mural do curso de Licenciatura em Física tem tido boa repercussão, uma vez que estudantes de diferentes cursos têm procurado o coordenador do projeto para obter maiores informações e para tecer elogios. Acredita-se que essa atividade esteja contribuindo para a formação de profissionais, de distintas áreas, com um olhar mais crítico quanto ao processo de produção de conhecimento científico e suas aplicações. Cabe salientar que para todos os casos, tanto dentro como fora da universidade, são indicadas aos interessados o acesso as versões online.

No ano de 2015, alguns jornais foram utilizados em uma disciplina básica para os ingressantes do curso de Licenciatura em Física para poderem fomentar o início da 
discussão sobre temas científicos e foram considerados como materiais com grande potencial para despertar a curiosidade dos estudantes.

A sociedade tem usufruído bem do jornal e os leitores têm tecido elogios e demonstrado interesse em ler outras edições, demonstrando que a utilização dos jornais apresenta-se como uma ferramenta rica que possibilita o estabelecimento de relações entre os conhecimentos de ciência e suas implicações na sociedade, permitindo que tópicos sobre ciência possam ser apresentados de forma acessível e desmistificando a Física como algo ao alcance apenas de cientistas.

\section{Referências}

ANDRADE, I. B.; MARTINS, I. Discursos de professores de Ciências sobre leitura. Em: IX Encontro Nacional de Pesquisa em Ensino de Física, Jaboticatubas, MG. Atas... Jaboticatubas: SBF, 2004. CD-ROM.

BRASIL. MINISTÉRIO DA EDUCAÇÃO. SECRETARIA DE EDUCAÇÃO MÉDIA E TECNOLÓGICA. PCNs+ Ensino Médio: orientações educacionais complementares aos Parâmetros Curriculares Nacionais. Ciências da Natureza, Matemática e suas Tecnologias. Brasília: MEC, SEMTEC, 2002. 144 p.

D'AGOSTIN, A. LEITE, A. E.; HIGA, I.; PAIVA, L. P.. Os estudantes do ensino médio e sua relação com a Física. Em: 58 ${ }^{a}$ Reunião da Sociedade Brasileira para o Progresso da Ciência, Florianópolis, Santa Catarina, 2006. Disponível em: http://www.sbpcnet.org.br/livro/58ra/SENIOR/RESUMOS/resumo 3601.html. Acesso em: 02/06/2016.

ERTHAL, J. P. C. Estabelecimento de relações entre a formação inicial de professores de Física e o ensino dessa disciplina para jovens e adultos: uma investigação pautada em atividades experimentais. 2011. Tese de Doutorado - Universidade Estadual do Norte Fluminense, Centro de Ciências e Tecnologias, Campos dos Goytacazes, 2011.

FONTANELLA, D.; MEGLHIORATTI, F. A. A divulgação científica e o ensino de ciências: análise das pesquisas. Em: VII Encontro Internacional de Produção Científica, Maringá, Paraná, 2013.2 Disponível em: http://www.cesumar.br/prppge/pesquisa/epcc2013/oit mostra/Denise Fontanella.pdf. Acesso em: 25/04/2016.

RIBEIRO, R. A.; KAWAMURA, M. R. D. Divulgação científica e ensino de física: intenções, funções e vertentes. Em: Atas do X Encontro de Pesquisa em Ensino de Física. Londrina, PR: $\quad$ SBF, 2006. Disponível em: http://www.sbf1.sbfisica.org.br/eventos/epef/x/atas/resumos/T0077-1.pdf. Acesso em 13/05/2016.

RICARDO, C. E.; FREIRE, J. C. A. A concepção dos alunos sobre a física do ensino médio: um estudo exploratório. Revista Brasileira de Ensino de Física, v. 29, n. 2, p.251-266, 2007.

Submissão: 12/06/2016

Aceite: 27/03/2017 